\title{
Correction to: Locomotion and postures of the Vietnamese pygmy dormouse Typhlomys chapensis (Platacanthomyidae, Rodentia): climbing and leaping in the blind
}

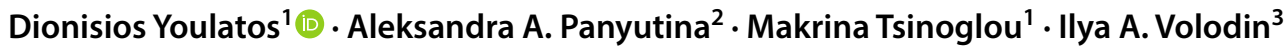

Published online: 10 July 2020

(c) Deutsche Gesellschaft für Säugetierkunde 2020

\section{Correction to: Mammalian Biology \\ https://doi.org/10.1007/s42991-020-00043-9}

The original version of this article unfortunately contained a mistake. The caption of Fig. 4 was incorrect. The corrected Fig. 4 caption is given below.

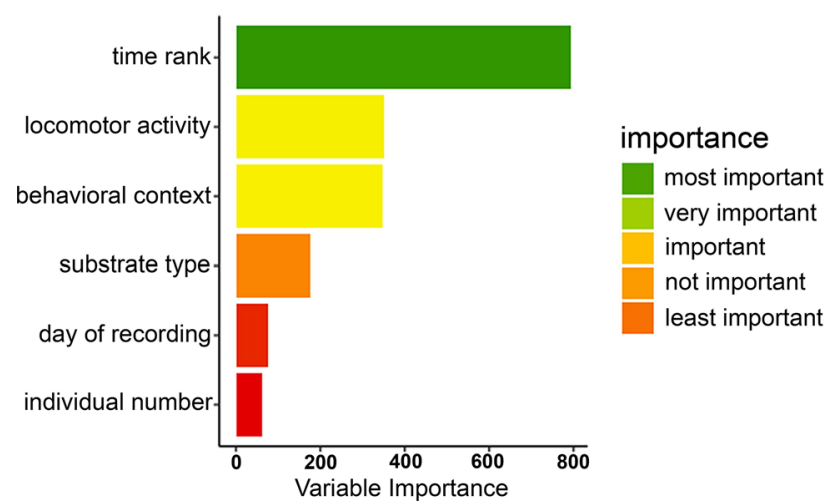

Fig. 4 Importance of different factors for predicting the emission of echolocation calls (pulse rate), using the random forest algorithm (yellow indicates an intermediate gradation between important and very important)

The original article can be found online at https://doi.org/10.1007/ s42991-020-00043-9.

Dionisios Youlatos

dyoul@bio.auth.gr

1 Department of Zoology, School of Biology, Aristotle University of Thessaloniki, Thessaloniki, Greece

2 Severtsov Institute of Ecology and Evolution, Russian Academy of Sciences, Moscow, Russia

3 Department of Vertebrate Zoology, Faculty of Biology, Lomonosov Moscow State University, Moscow, Russia
Publisher's Note Springer Nature remains neutral with regard to jurisdictional claims in published maps and institutional affiliations. 